\title{
The incidence, risk factors and prognosis of acute kidney injury in severe and critically ill patients with COVID-19 in mainland China: a retrospective study
}

\section{Ling Sang}

State Key Laboratory of Respiratory Diseases, Guangzhou Institute of Respiratory Health, The First Affiliated Hospital of Guangzhou Medical University, Department of Pulmonary and Critical Care Medicine, Guangzhou, China https://orcid.org/0000-0001-5466-6834

\section{Sibei Chen}

State Key Laboratory of Respiratory Diseases, Guangzhou Institute of Respiratory Health, The First Affiliated Hospital of Guangzhou Medical University, Department of Pulmonary and Critical Care Medicine, Guangzhou, China

\section{Xia Zheng}

The First Affiliated Hospital of Zhejiang University, Department of Critical Care Medicine,Hangzhou, Zhejiang, China.

\section{Weijie Guan}

State Key Laboratory of Respiratory Diseases, Guangzhou Institute of Respiratory Health, The First Affiliated Hospital of Guangzhou Medical University, Department of Pulmonary and Critical Care Medicine, Guangzhou, China

\section{Zhihui Zhang}

State Key Laboratory of Respiratory Diseases, Guangzhou Institute of Respiratory Health, The First Affiliated Hospital of Guangzhou Medical University, Department of Pulmonary and Critical Care Medicine, Guangzhou, China

\section{Wenhua Liang}

The State Key Laboratory of Respiratory Disease, Guangzhou Institute of Respiratory Disease, The First Affiliated Hospital of Guangzhou Medical University, Department of Thorax surgery, Guangzhou, China

\section{Ming Zhong}

Department of Critical Care Medicine, Zhongshan Hospital Fudan University, Shanghai, China.

\section{Li Jiang}

Department of Critical Care Medicine, Xuanwu Hospital, Capital Medical University $\varangle$ Beijing $₫$ China

\section{Chun Pan}

Department of Critical Care Medicine, Zhongda Hospital, Southeast University, Nanjing,China $₫$

\section{Wei Zhang}

Emergency Department, the 900th Hospital of Joint Service Corps of Chinese PLA囚FuZhou, China.

\section{Jiaan Xia}


Department of tuberculosis s, Wuhan Jinyintan Hospital, Wuhan, China

\section{Nanshan Chen}

Department of respiratory and critical care medicine Wuhan jinyintan hospital. Wuhan, China .

\section{Wenjuan Wu}

Department of Critical Care Medicine, Wuhan Jinyintan Hospital, Wuhan, China

\section{Hongkai Wu}

State Key Laboratory of Respiratory Disease, National Clinical Research Center for Respiratory Disease, The First Affiliated Hospital of Guangzhou Medical University, Guangzhou Medical University,

\section{Yonghao Xu}

State Key Laboratory of Respiratory Diseases, Guangzhou Institute of Respiratory Health, The First Affiliated Hospital of Guangzhou Medical University, Department of Pulmonary and Critical Care Medicine, Guangzhou, China

\section{Xuesong Liu}

State Key Laboratory of Respiratory Diseases, Guangzhou Institute of Respiratory Health, The First Affiliated Hospital of Guangzhou Medical University, Department of Pulmonary and Critical Care Medicine, Guangzhou, China

\section{Xiaoqing Liu}

State Key Laboratory of Respiratory Diseases, Guangzhou Institute of Respiratory Health, The First Affiliated Hospital of Guangzhou Medical University, Department of Pulmonary and Critical Care Medicine, Guangzhou, China

\section{Jianxing He ( $\sim$ hejx@vip.163.com )}

The State Key Laboratory of Respiratory Disease, Guangzhou Institute of Respiratory Disease, The First Affiliated Hospital of Guangzhou Medical University, Department of Thorax surgery $₫$ Guangzhou, China

\section{Shiyue Li ( $\sim$ lishiyue@vip.188.com )}

State Key Laboratory of Respiratory Diseases, Guangzhou Institute of Respiratory Health, The First Affiliated Hospital of Guangzhou Medical University, Department of Pulmonary and Critical Care Medicine, Guangzhou, China

\section{Dingyu Zhang ( $\nabla$ 1813886398@qq.com )}

Research Center for Translational Medicine, Wuhan Jinyintan Hospital, Wuhan, China

\section{Nanshan Zhong ( $\square$ nanshan@vip.163.com)}

State Key Laboratory of Respiratory Diseases, Guangzhou Institute of Respiratory Health, The First Affiliated Hospital of Guangzhou Medical University, Department of Pulmonary and Critical Care Medicine, Guangzhou, China

\section{Yimin Li ( $\square$ dryiminli@vip.163.com )}

State Key Laboratory of Respiratory Diseases, Guangzhou Institute of Respiratory Health, The First Affiliated Hospital of Guangzhou Medical University, Department of Pulmonary and Critical Care Medicine, Guangzhou, China

\section{Research Article}


Keywords: Corona Virus Disease 2019(Covid-19); Acute Respiratory Distress Syndrome(ARDS); Acute Kidney Injury(AKI); Intensive Care Unit(ICU); Mechanical Ventilation(MV)

Posted Date: July 30th, 2020

DOI: https://doi.org/10.21203/rs.3.rs-50431/v1

License: (c) (1) This work is licensed under a Creative Commons Attribution 4.0 International License. Read Full License

Version of Record: A version of this preprint was published at BMC Pulmonary Medicine on November 9th, 2020. See the published version at https://doi.org/10.1186/s12890-020-01305-5. 


\section{Abstract}

Background: Since the clinical correlates, prognosis and determinants of AKI in patients with Covid-19 remain largely unclear, we perform a retrospective study to evaluate the incidence, risk factors and prognosis of AKI in severe and critically ill patients with Covid-19.

Methods: We reviewed medical records of all adult patients (>18 years) with laboratory-confirmed Covid19 who were admitted to the intensive care unit (ICU) between January $23^{\text {rd }} 2020$ and April $6^{\text {th }} 2020$ at Wuhan JinYinTan Hospital and The First Affiliated Hospital of Guangzhou Medical University. The clinical data, including patient demographics, clinical symptoms and signs, laboratory findings, treatment [including respiratory supports, use of medications and continuous renal replacement therapy (CRRT)] and clinical outcomes, were extracted from the electronic records, and we access the incidence of AKI and the use of CRRT, risk factors for AKI, the outcomes of renal diseases, and the impact of AKI on the clinical outcomes.

Results: Among 210 subjects, 131 were males (62.4\%). The median age was 64 years (IQR: 56-71). Of 92 (43.8\%) patients who developed AKI during hospitalization, 13 (14.1\%), 15 (16.3\%) and 64 (69.6\%) patients were classified as stage 1, 2 and 3, respectively. 54 cases (58.7\%) received CRRT. Age, sepsis, Nephrotoxic drug, IMV and elevated baseline Scr were associated with AKI occurrence. The renal recover during hospitalization among 16 AKI patients (17.4\%), who had a significantly shorter time from admission to AKI diagnosis, lower incidence of right heart failure and higher P/F ratio. Of 210 patients, 93 patients deceased within 28 days of ICU admission. AKI stage 3 , critical disease, greater age and minimum $P / F<150 \mathrm{mmHg}$ independently associated with it.

Conclusions: Among patients with Covid-19, the incidence of AKI was high. age, sepsis, nephrotoxic drug, IMV and baseline Scr were strongly associated with the development of AKI. Time from admission to AKI diagnosis, right heart failure and $\mathrm{P} / \mathrm{F}$ ratio were independently associated with the potential of renal recovery. Finally, AKI KIDGO stage 3 independently predicted the risk of death within 28 days of ICU admission.

\section{Background}

Since December 2019, the outbreak of coronavirus disease 2019 (Covid-19) has resulted in more than 10 million laboratory-confirmed cases and 499,913 death cases worldwide up to June 29th 2020 (1). The clinical manifestations of Covid-19 have been heterogeneous, ranging from asymptomatic viral carriers to critically ill cases (2.3). The clinical outcomes of critically ill cases have been poor, with the mortality rate being $61.5 \%$ within 28 days (4). Identification of the risk factors of death would be crucial to inform clinical decisions to guide early triage of patients for more intensive monitoring. Previous studies have documented that greater age and the presence of comorbidities correlated significantly with death in patients with Covid-19 (5). Few studies, however, have focused on the systemic complications and the clinical outcomes of Covid-19. 
Acute kidney injury (AKI) is a heterogeneous disease and a common complication in critically ill patients. Severe respiratory infections such as Covid-19 might predispose to the development of AKI. Indeed, AKI reportedly correlated with poor clinical outcomes in patients with Covid-19 $(2,3,4,6,7)$. Nonetheless, the clinical correlates, prognosis and determinants of AKI in patients with Covid-19 remain largely unclear. Early identification and intervention would help improve the clinical outcomes of patients with Covid-19 who were prone to develop AKI $(8,9)$. Therefore, we performed a retrospective study to evaluate the incidence, risk factors and prognosis of AKI in severe and critically ill patients with Covid-19.

\section{Methods}

\section{Patients}

We reviewed medical records of all adult patients (>18 years) with laboratory-confirmed Covid- 19 who were admitted to the intensive care unit (ICU) between January 23rd 2020 and April 6th 2020 at Wuhan JinYinTan Hospital and The First Affiliated Hospital of Guangzhou Medical University (designated hospitals for admitting patients with Covid-19). All patients met the criteria of having severe or critical Covid-19 according to the Chinese guidelines (10). The Ethics Committees of both hospitals approved the study protocol. Informed consent was waived due to the nature of the retrospective study.

\section{Data extraction}

The clinical data from 210 cases, including patient demographics, clinical symptoms and signs, laboratory findings, treatment [including respiratory supports, use of medications and continuous renal replacement therapy (CRRT)] and clinical outcomes, were extracted from the electronic records by two independent intensivists (LS and XZ) who subsequently cross-checked for data accuracy. The disagreement was further adjudicated by a third independent reviewer (YML). All data were entered into the computerized database for further statistical analyses.

\section{Study definitions}

Severe Covid-19 met any of the following: (1) Respiratory distress, RR $\geq 30$ times/min, with cyanosis; (2) Arterial finger oxygen saturation $\leq 93 \%($ air); (3) $\mathrm{PaO} 2 / \mathrm{FiO} 2 \leq 300 \mathrm{mmHg}(1 \mathrm{mmHg}=0.133 \mathrm{kPa})$. Critical Covid-19 met any of the following: (1) Respiratory failure requires mechanical ventilation; (2) Shock; (3) Multiple organ failure requires ICU life support(10).

The definition, severity staging and clinical management of AKI were based on the Kidney Disease: Improving Global Outcomes (KDIGO) classification (9). The clinical management could also be amended as per the clinical needs at the discretion of the attending clinicians $(11,12)$. Recovery of AKI was defined based on Acute Disease Quality Initiative (ADQI) 16 Workgroup: 
(1) rapid sustained reversal: recovery from AKI within $48 \mathrm{~h}$, (2) late sustained reversal: reversal after 48 hrs and sustained through 28 days after AKI diagnosis or hospital discharge, (3) relapsing AKI with complete recovery, (4) relapsing AKI without complete recovery and (5) never recovery. The first three categories were classified as complete renal recovery while the last two categories were classified as renal non-recovery (13).

\section{Study outcomes}

The study outcomes mainly consisted of the incidence of AKI and the use of CRRT. We also assessed the risk factors for AKI, the outcomes of renal diseases, and the impact of AKI on the clinical outcomes of Covid-19.

\section{Statistical analysis}

Continuous variables were expressed as the median and interquartile ranges (IQRs) and compared with Wilcoxon rank-sum test. Categorical variables were expressed as counts and percentages, and compared using chi-square test or Fisher's exact test as appropriate. The risk factors for AKI were screened with univariate logistic regression model, and the variables with $P$ value of 0.10 or less were considered as the potential risk factors and further imported into the multivariate logistic regression analysis. The AKI and survivor risk model was established by calculating the regression coefficient ( $\beta$ ), odds ratio (OR) and $95 \%$ confidence interval. The significance threshold was set at a 2-sided $P$ value of less than 0.05 . All statistical analyses were performed using $R$ version 3.5.1 software (the R Foundation, USA) or SPSS version 17.0 (SPSS Inc., USA).

\section{Results}

\section{Patient characteristics stratified by the severity of Covid-19}

We included 210 patients with completed data, of whom 131 were males $(62.4 \%)$. The median age was 64 years (IQR: 56-71). The patient characteristics as stratified by the disease severity are shown in Table E1. 60 patients were categorized as having severe disease and the remaining 150 patients as having critical disease upon admission to ICU. The gender and the age were comparable. Diabetes was more common in critical cases than in severe cases $(24.7 \%$ vs $11.7 \%, P=0.037)$. There were, however, no significant differences for other comorbidities between severe and critical cases.

Overall, the most common respiratory support for severe cases consisted of conventional oxygen therapy (COT) and high-flow nasal cannula (HFNC), A significantly larger proportion of patients with critical

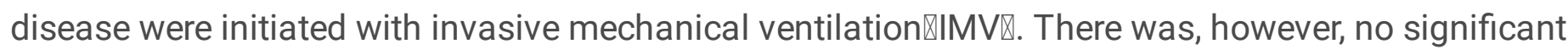
difference in the use of non-invasive mechanical ventilation (NIV) between severe and critical cases. पTable E10 
Of the 210 patients, 194 patients were from Wuhan JinYinTan Hospital, and 16 patients were from The First Affiliated Hospital of Guangzhou Medical University. Right heart failure,

Hypoxemia , hypercapnia and higher levels of interleukin-6 were more common in patients from Wuhan JinYinTan Hospital (both $P<0.05$ ). $\otimes$ Table E2ロ

\section{The incidence of AKI and use of CRRT, and the Risk factors associated with AKI}

Of 92 (43.8\%) patients who developed AKI during hospitalization, 13 (14.1\%), 15 (16.3\%) and 64 (69.6\%) patients were classified as having stage 1, 2 and 3 disease, respectively (Table 1). 54 cases (58.7\%) received CRRT.

Patients with AKI were significantly more likely to be critical cases ( $97.8 \%$ vs. $50.9 \%, P<0.001)$, have malignancy $(10.9 \%$ vs. $3.4 \%, P=0.031)$, develop sepsis $(78.3 \%$ vs. $33.9 \%, P<0.001)$, right heart failure $(30.4 \%$ vs. $13.6 \%, P=0.003)$ and disseminated intravascular coagulation $(29.4 \%$ vs. $4.2 \%, P<0.001)$.

Significantly more critical cases than severe cases who received nephrotoxic drugs developed AKI (41.3\% vs. $11.9 \%, P<0.001)$. Patients with AKI more frequently received IMV ( $87.0 \%$ vs. $32.2 \%, P<0.001)$ but less frequently received COT $(2.2 \%$ vs. $33.1 \%, P<0.001)$ and NIV $(4.4 \%$ vs. $21.2 \%, P<0.001)$. Furthermore, patients with AKI had markedly higher levels of serum creatinine (median: $75.5 \mathrm{vs} .67 .1 \mu \mathrm{mol} / \mathrm{L}, P=0.002$ ), interleukin-6 (median: 17.9 vs. $12.3 \mathrm{pg} / \mathrm{ml}, P<0.001$ ) and serum ferritin (median: $2001.0 \mathrm{vs.} 985.4 \mathrm{ng} / \mathrm{ml}$, $P<0.001$ ). Hypoxemia and hypercapnia were also more frequently identified in patients with AKI (both $P<0.001)$. In the multivariate regression model, greater age(OR 1.05,95\% $\mathrm{Cl} 1.01-1.09)$,

sepsis(OR2.82,95\%1.14-6.98), Nephrotoxic drug(OR2.67, 95\%1.09-6.55), IMV(OR9.72, 95\%2.93-32.24) and elevated baseline Scr(OR1.01, 95\%1.00-1.02) were associated with AKI occurrence among patients with Covid-19. (Table 2)

\section{Outcomes of renal diseases and impact of AKI on clinic outcomes}

Of 92 patients with AKI, the renal function improved during hospitalization among 16 patients (17.4\%), who had a significantly shorter time from admission to AKI diagnosis (median: 5 vs. 9 days, $P<0.001$ ), lower incidence of right heart failure ( $56.3 \%$ vs. $25.0 \%, P=0.030)$ and higher $\mathrm{P} / \mathrm{F}$ ratio (median: $133.5 \mathrm{vs.}$ $67.0, P<0.001$ ) than their counterparts (Table 3) (Fig 1)

Of 210 patients, 93 patients deceased within 28 days of ICU admission (ICU 28-day mortality: 44.3\%), and non-survivors were more likely to be critical cases compared with severe cases $(98.9 \%$ vs. $1.1 \%, P<0.001)$. Significantly more non-survivors had sepsis $(77.4 \%$ vs. $34.2 \%, P<0.001)$ acute kidney injury stage 3 $(52.7 \%$ vs. $12.8 \%, P<0.001)$ and disseminated intravascular coagulation $(28.0 \%$ s. $5.1 \%, P<0.001)$. CRRT was initiated significantly more frequently in non-survivors than in survivors $(41.9 \%$ vs. $12.8 \%, P<0.001)$. 
IMV was initiated more frequently whereas COT and HFNC were initiated less frequently in critical cases (all $P<0.01$ ). Non-survivors had higher levels of interleukin-6 (median: 17.2 vs. $13.6 \mathrm{pg} / \mathrm{ml}, P=0.031$ ) and serum ferritin (median: 2001.0 vs. $1000.7 \mathrm{ng} / \mathrm{ml}, P<0.001$ ) compared with survivors. Hypoxemia and hypercapnia were also more common in non-survivors (both $P<0.001$ ). However, neither the use of nephrotoxic drugs nor the serum creatinine levels differed between survivors and non-survivors (Table 4). After adjusting for the potential confounding factors, having KDIGO stage 3 (OR:5.33, 95\%Cl: 1.15-24.65), critical disease (OR: 69.16, 95\%Cl: 5.86-815.79) , greater age (OR: 1.06, 95\%Cl: 1.02-1.11) and Min P/F $<150 \mathrm{mmHg}$ (OR: $15.21,95 \% \mathrm{Cl}$ : 4.72-49.07) independently predicted the death within 28 days of ICU admission(Table 5) (Fig 2).

\section{Discussion}

This is the first and largest, up to date, study which investigates the association between AKI and clinical outcomes in severe and critical patients with Covid-19. Among patients with Covid-19, the incidence of any $\mathrm{AKI}$ stages, AKI stage 1, 2, 3 was $43.8 \%, 14.1 \%, 16.3 \%$ and $69.6 \%$, respectively. age, sepsis, nephrotoxic drug, IMV and baseline Scr were strongly associated with the development of AKI. 58.7\% of patients received CRRT, and only $17.4 \%$ of patients with AKI achieved recovery of the renal function, time from admission to $\mathrm{AKI}$ diagnosis, right heart failure and $\mathrm{P} / \mathrm{F}$ ratio were independently associated with the potential of renal recovery. It is worth emphasizing that all dialysis-dependent AKI patients were treated with CRRT. Furthermore, greater age, severe hypoxemia, having severe AKI and critical Covid-19 independently predicted the risk of death within 28 days of ICU admission.

AKI has been a frequent complication among patients admitted to the ICU. A 2004-2012 systematic review that included large-scale cohort studies has estimated the global incidence of AKI to be $21.6 \%$ in adults (95\% Cl, 19.3 to 24.1$)$, and $31.7 \%(95 \% \mathrm{Cl}, 28.6$ to 35.0$)$ in critical care settings, according to the KDIGO guideline (14). However, a recent study which enrolled 634 patients with ARDS demonstrated that an incidence rate of $68.3 \%$ for AKI after the onset of ARDS (15). In another observational study on the critically ill patients with 2009 influenza A (H1N1) viral pneumonia, the incidence of AKI reached to 51\% (16). Our finding of the higher incidence of AKI (43.8\%) in patients with Covid-19 therefore might have been attributable to the high incidence of ARDS during hospitalization.

Previous studies had demonstrated that greater age, sepsis and baseline Scr was associated with the development of AKI in adult patients $(10,15,17,18,19,20,21)$, our results were consistence with this view. In recent years, the association between IMV and AKI in ARDS patients had attracted attention and became widely acceptable. Several studies had postulated that IMV might played a key role in the development of AKI due to the mechanisms of lung-kidney crosstalk(22,23), and lung protective ventilation strategy

including low tidal volume ventilation, limited plateau pressure, and suitable PEEP level was postulated to decrease the risk of $\mathrm{AKI}(24)$. However, hypercapnia was very common in our patients, especially the patients with AKI. And it seemed to be difficult to correct even the patients had been intubated and received lung protective ventilation strategy, which was not displayed in our study. So the physicians had to relax restrictions on tidal volume and plateau pressure in a very constrained environment, especially at 
the early stage of epidemic. And it might explain the reason IMV was the strongest risk factors associated with AKI in our study.

In our study, only $16 \mathrm{AKI}$ patients (17.4\%) had achieved recovery of renal function during the hospitalization, which was significantly lower than that reported in a previous study $(39.3 \%)^{\llbracket 25}$. Our analysis revealed that the delayed onset of AKI, the presence of right heart failure and lower oxygenation ratio were associated with an increased likelihood of having non-recovery of renal function. It was likely that patients with a delayed onset AKI would have a lengthy course of hospital management, including hemodynamic deterioration, use of drug with nephrotoxicity and the adverse impacts associated with lung-renal cross-talk during the course of ARDS development $(18,19)$. Severe hypoxemia had been considered as a cause of chronic kidney disease and $\operatorname{AKI}(26,27,28)$. it seemed that the severity and duration of AKI likely depend on the severity and duration of hypoxemia. In our study, the overall incidence of right heart failure was similar with a previous study(29). Persistent right heart failure would lead to elevated central venous pressure and peripheral edema, which were risk factors of AKI in critically illness(30).

Several previous studies had demonstrated that AKI, especially severe AKI was associated with poorer clinical outcomes $(15,18,31)$. The AKI-EPI study showed that patients with stage 1 AKI did not have a higher risk of mortality compared to patients without AKI(32). However, in our study, only AKI KDIGO stage 3 was associated with ICU 28 days mortality, patients with KDIGO stage 1 and 2 AKI did not have a higher mortality compared to patients without AKI.

To our knowledge, this is the first and largest study which investigates the incidence, risk factors of AKI, and the association between AKI and clinical outcomes in severe and critical patients with Covid-19. However, we acknowledge a number of limitations of the current study, which are in part due to the nature of retrospective study. We did not collect the ventilator parameters which might play a key role in lungkidney crosstalk. We also did not access the cumulation of fluid balance per day due to the very constrained environment, and the result of our study needed further validation in the future study

\section{Conclusion}

In conclusion, Among patients with Covid-19, the incidence of AKI was high. age, sepsis, nephrotoxic drug, IMV and baseline Scr were strongly associated with the development of AKI. Time from admission to $\mathrm{AKI}$ diagnosis, right heart failure and P/F ratio were independently associated with the potential of renal recovery. Finally, AKI KIDGO stage 3 independently predicted the risk of death within 28 days of ICU admission.

\section{Abbreviations}

Covid-19: Corona Virus Disease 2019; ARDS: Acute Respiratory Distress Syndrome; AKI: Acute Kidney Injury; ICU: Intensive Care Unit; MV: Mechanical Ventilation; CRRT: continuous renal replacement therapy; 
P/F: $\mathrm{PaO}_{2} / \mathrm{FiO}_{2}$; KIDGO: Kidney Disease: Improving Global Outcomes; ADQI: Acute Disease Quality Initiative; IQRs: interquartile ranges; OR: odds ratio; COT: conventional oxygen therapy; HFNC: high-flow nasal cannula; IMV: invasive mechanical ventilation; NIV: non-invasive mechanical ventilation.

\section{Declarations}

\section{Acknowledgements}

Not Applicable.

\section{Authors' contributions}

JXH, SYL, DYZ, NSZ and YML conceived and designed the study; ZHZ, WHL, MZ, LJ, CP, WZ, JAX, NSC, WJW, YHX, XSL and XQL collected and aggregated data; LS, SBC, XZ, WJG and HKW analyzed the data and wrote the manuscript. All authors read and approved the final manuscript.

\section{Funding}

The study was funded by the National Science and Technology Major Project (No.2017ZX10204401), National Natural Science Foundation of China (No.81970071), National Key Research and Development Program of China (No.2018YFC1200100), the Special Project of Guangdong Science and Technology Department (No.2020B111105001), and Natural Science Foundation of Guangdong(No.2020A1515011459). The funding body had no role in the study design, the collection, analysis or interpretation of the data.

\section{Availability of data and materials}

Data sharing will be considered only on a collaborative basis with the principal investigators, after evaluation of the proposed study protocol and statistical analysis plan.

\section{Ethical approval and consent to participate}

The Ethics Committees of Wuhan JinYinTan Hospital and the First Affiliated Hospital of Guangzhou Medical University approved the protocol(KY-2020-56.01/GY-2020-65). Since all data were anonymously used and this study does not contain protected health information, the ethics committee approved a waiver of the requirement for informed consent. 


\section{Consent for publication}

Not Applicable.

\section{Competing interests}

None of the authors has any conflict of interest to report.

\section{References}

1. Coronavirus disease (COVID-19) Situation Report- 161. Available from: https://www.who.int/docs/default-source/coronaviruse/situation-reports/20200629-covid-19-sitrep161.pdf?sfvrsn=74fde64e_2

2. Chen N, Zhou M, Dong X, et al. Epidemiological and clinical characteristics of 99 cases of 2019 novel coronavirus pneumonia in Wuhan, China: a descriptive study[J]. Lancet, 2020, 395(10223):507-513

3. Guan WJ, Ni ZY, Hu Y, et al. Clinical characteristics of coronavirus disease 2019 in China[J]. N Engl J Med, 2020, 382(18): 1708-1720. DOI: 1056/NEJMoa2002032.

4. Yang $X, Y u Y, X u$ J, et al. Clinical course and outcomes of critically ill patients with SARS-CoV-2 pneumonia in Wuhan, China: a single-centered, retrospective, observational study [J]. Lancet Respir Med, 2020, 8(5):475-481. DOI: 1016/S2213-2600(20)30079-5

5. Guan W J , Liang W H , Zhao Y, et al. Comorbidity and its impact on 1590 patients with Covid-19 in China: A Nationwide Analysis[J]. Eur Respir J, 2020:2000547. DOI: 10.1183/13993003.00547-2020.

6. Wang D, Hu B, Hu C, et al. Clinical characteristics of 138 hospitalized patients with 2019 novel coronavirus-infected pneumonia in Wuhan, China[J]. JAMA, 2020, In press. DOI:

10.1001/jama.2020.1585.

7. Cheng YC, Luo R, Wang $\mathrm{K}$, et Kidney disease is associated with in hospital death of patients with COVID-19 Kidney Int. 2020 May;97(5):829-838. DOI: 10.1016/j.kint.2020.03.005.

8. Komaru Y, Inokuchi R, Iwagami M, et al. Inverse Correlation Between Incidence and Mortality of Acute Kidney Injury in Critically III Patients: A Systematic Review[J]. Shock, 2020区 In press. DOI: 10.1097/SHK.0000000000001511.

9. Palevsky, P.M.; Liu, K.D.; Brophy, P.D; et al. KDOQI US Commentary on the 2012 KDIGO Clinical Practice Guideline for Acute Kidney Injury. Am. J. Kidney Dis. 2013, 61, 649-672.

10. National Health Commission of the People's Republic of Available from:

http://www.nhc.gov.cn/yzygj/s7653p/202003/46c9294a7dfe4cef80dc7f5912eb1989.shtml. Accessed on 4 March 2020 
11. Singer M, Deutschman CS, Seymour CW, et al. The Third International Consensus Definitions for Sepsis and Septic Shock (Sepsis-3). JAMA, 315:801-10

12. Taylor FB Jr, Toh CH, Hoots WK, et al. Towards definition, clinical and laboratory criteria, and a scoring system for disseminated intravascular coagulation. Thromb Haemost. 2001;86:1327-1330

13. Chawla LS, Bellomo R, Bihorac A, et al. Acute kidney disease and renal recovery: consensus report of the acute disease quality initiative (ADQI) 16 workgroup. Nat Rev Nephrol. 2017;13:241-57.

14. Susantitaphong P, Cruz D N, Cerda J, et al. World incidence of AKI: a meta-analysis[J]. Clin J Am Soc Nephrol , 2013, 8(9): 1482-1493.

15. Panitchote A, Mehkri $O$, Hasting A, et al. Factors associated with acute kidney injury in acute respiratory distress syndrome[J]. Ann intensive care, 2019, 9(1): 74

16. Nin N, Lorente J A, Soto L, et al. Acute kidney injury in critically ill patients with 2009 influenza $A$ (H1N1) viral pneumonia: an observational study[J]. Intensive care med, 2011, 37(5): 768-774

17. Fuhrman DY, Kane-Gill S, Goldstein SL, et al. Acute kidney injury epidemiology, risk factors, and outcomes in critically ill patients 16-25 years of age treated in an adult intensive care unit. Ann Intensive Care. 2018;8(1):26.

18. Xu X, Nie S, Liu Z, et al. Epidemiology and clinical correlates of AKI in Chinese hospitalized adults. Clin J Am Soc Nephrol. 2015;10(9):1510-8.

19. Zarbock A, Gomez H, Kellum J A et al. Sepsis-induced AKI revisited: pathophysiology, prevention and future therapies[J]. Curr Opin Crit Care. 2014;20(6):588-95. DOI: 10.1097/MCC.0000000000000153.

20. Palmieri T, Lavrentieva A, Greenhalgh D G et al. Acute kidney injury in critically ill burn patients. Risk factors, progression and impact on mortality[J]. Burns, 2010, 36(2): 205-211.

21. Parolari $A$, Pesce $L L$, Pacini $D$, et al. Risk factors for perioperative acute kidney injury after adult cardiac surgery: role of perioperative management[J]. Ann Thorac Surg. 2012;93(2):584-91. doi: 1016/j.athoracsur.2011.09.073.

22. van den Akker JP, Egal M, Groeneveld $A B$ et al. Invasive mechanical ventilation as a risk factor for acute kidney injury in the critically ill: a systematic review and meta-analysis. Crit Care. 2013;17(3):R98.

23. Lombardi R, Nin N, Penuelas 0 , et al. Acute kidney injury in mechanically ventilated patients: the risk factor profile depends on the timing of Aki onset. Shock. 2017;48(4):411-7.

24. Ranieri VM, Giunta F, Suter PM, et al. Mechanical ventilation as a mediator of multisystem organ failure in acute respiratory distress syn- drome. JAMA. 2000;284(1):43-4.

25. Panitchote A, Mehkri $O$, Hasting A, et al. Clinical predictors of renal non-recovery in acute respiratory distress syndrome[J]. BMC nephrology, 2019, 20(1): 255.

26. Samanta A, Patra A, Mandal S, et al. Hypoxia: A cause of acute renal failure and alteration of gastrointestinal microbial ecology[J]. Saudi J Kidney Dis Transpl. 2018;29(4):879-888. DOI: 10.4103/1319-2442.239653. 
27. Haase $V$ Mechanisms of hypoxia responses in renal tissue[J]. J Am Soc Nephrol. 2013;24(4):537-41. DOI: 10.1681/ASN.2012080855.

28. Fu Q, Colgan S P, Shelley C S. Hypoxia: the force that drives chronic kidney disease[J]. Clin Med Res. 2016 Mar;14(1):15-39. doi: 3121/cmr.2015.1282.

29. Dessap A M, Boissier F, Charron C, et al. Acute cor pulmonale during protective ventilation for acute respiratory distress syndrome: prevalence, predictors, and clinical impact[J]. Intensive care med, 2016, 42(5): 862-870.

30. Chen K P, Cavender S, Lee J, et al. Peripheral edema, central venous pressure, and risk of AKI in critical illness[J]. Clin J Am Soc Nephrol. 2016;11(4):602-8. DOI: 10.2215/CJN.08080715.

31. Paudel M S, Wig N, Mahajan S, et al. A study of incidence of AKI in critically ill patients[J]. Ren Fail. 2012;34(10):1217-22. DOI: 3109/0886022X.2012.723515.

32. Hoste EA, Bagshaw SM, Bellomo R, et al. Epidemiology of acute kidney injury in critically ill patients: the multinational AKI-EPI study. Intensive Care Med. 2015;41(8):1411-2. DOI: 10.1007/s00134-0153934-7.

\section{Tables}

Table 1. Clinical characteristics of patients with Covid-19 when stratified by the presence of AKI during hospitalization 


\begin{tabular}{|c|c|c|c|c|}
\hline Total & & AKI & No AKI & \\
\hline Characteristic & $(N=210)$ & $(n=92)$ & $(n=118)$ & $\begin{array}{l}P \\
\text { value }\end{array}$ \\
\hline Age, median (IQR), yrs & $64(56-71)$ & $65(59-73)$ & $62(54-70)$ & 0.021 \\
\hline Sex & & & & 0.186 \\
\hline Female & $79(37.6)$ & $30(32.6)$ & $49(41.5)$ & - \\
\hline Male & $131(62.4)$ & $62(67.4)$ & $69(58.5)$ & - \\
\hline Severity of Covid-19 & & & & $<0.001$ \\
\hline Severe & $60(28.6)$ & $2(2.2)$ & $58(49.2)$ & - \\
\hline Critical & $150(71.4)$ & $90(97.8)$ & $60(50.9)$ & - \\
\hline \multicolumn{5}{|l|}{ Comorbidities } \\
\hline Hypertension & $98(46.7)$ & $45(48.9)$ & $53(44.9)$ & 0.565 \\
\hline Diabetes & $44(21.0)$ & $23(25.0)$ & $21(17.8)$ & 0.203 \\
\hline Cardiovascular diseases & $23(11.0)$ & $9(9.8)$ & $14(11.9)$ & 0.632 \\
\hline Malignancy & $14(6.7)$ & $10(10.9)$ & $4(3.4)$ & 0.031 \\
\hline Cerebrovascular disease & $12(5.7)$ & $6(6.52)$ & $6(5.1)$ & 0.656 \\
\hline Chronic Kidney Disease & $10(4.8)$ & $6(6.52)$ & $4(3.4)$ & 0.290 \\
\hline $\begin{array}{l}\text { Chronic Obstructive } \\
\text { Pulmonary Disease }\end{array}$ & $5(2.4)$ & $2(2.2)$ & $3(2.5)$ & NA \\
\hline Connective Tissue Disease & $2(1.0)$ & $2(2.2)$ & $0(0.0)$ & NA \\
\hline \multicolumn{5}{|l|}{ Complication } \\
\hline Sepsis & $112(53.3)$ & $72(78.3)$ & 40 (33.9) & $<0.001$ \\
\hline Right heart failure & $44(21.0)$ & $28(30.4)$ & $16(13.6)$ & 0.003 \\
\hline $\begin{array}{l}\text { Disseminated Intravascular } \\
\text { Coagulation }\end{array}$ & $32(15.2)$ & $27(29.4)$ & $5(4.24)$ & $<0.001$ \\
\hline \multicolumn{5}{|l|}{ Treatment } \\
\hline Drug with Nephrotoxicity & $52(24.8)$ & $38(41.3)$ & $14(11.9)$ & $<0.001$ \\
\hline Respiratory support: COT & $41(19.5)$ & $2(2.2)$ & $39(33.1)$ & $<0.001$ \\
\hline Respiratory support: HFN & $22(10.5)$ & $6(6.5)$ & $16(13.6)$ & 0.099 \\
\hline Respiratory support: NIV & $29(13.8)$ & $4(4.4)$ & $25(21.2)$ & $<0.001$ \\
\hline Respiratory support: IMV & $118(56.2)$ & $80(87.0)$ & $38(32.2)$ & $<0.001$ \\
\hline
\end{tabular}




\begin{tabular}{|c|c|c|c|c|}
\hline \multicolumn{5}{|l|}{ Laboratory Findings } \\
\hline $\begin{array}{l}\text { Baseline serum creatinine } \\
(\mu \mathrm{mol} / \mathrm{L})\end{array}$ & $69.7(55.9-85.9)$ & $75.5(59.8-102.8)$ & $67.1(54.3-78.4)$ & 0.002 \\
\hline Maximum $\mathrm{PaCO}_{2}(\mathrm{mmHg})$ & $52.0(39.0-73.8)$ & $69.5(46.8-81.3)$ & $45.0(38.3-57.5)$ & $<0.001$ \\
\hline Maximum $\mathrm{PaCO}_{2}>=60 \mathrm{mmHg}$ & $82(39.05)$ & $55(59.78)$ & $27(22.88)$ & $<0.001$ \\
\hline $\begin{array}{l}\text { Minimum } \mathrm{PaO} 2 / \mathrm{FiO} 2 \text { ratio } \\
(\mathrm{mmHg})\end{array}$ & $\begin{array}{l}109.0(65.0- \\
207.7)\end{array}$ & $73.0(62.8-138.6)$ & $\begin{array}{l}169.0(74.3- \\
217.5)\end{array}$ & $<0.001$ \\
\hline $\begin{array}{l}\text { Minimum } \mathrm{PaO} 2 / \mathrm{FiO} 2 \text { ratio } \\
<150 \mathrm{mmHg}\end{array}$ & $116(55.24)$ & $70(76.09)$ & $46(38.98)$ & $<0.001$ \\
\hline Maximum IL-6 (pg/ml) & $14.3(9.9-24.9)$ & $17.9(12.6-33.5)$ & $12.3(8.9-19.6)$ & $<0.001$ \\
\hline $\begin{array}{l}\text { Maximum serum ferritin } \\
(\mathrm{ng} / \mathrm{ml})\end{array}$ & $\begin{array}{l}1607.8(786.2- \\
2001.0)\end{array}$ & $\begin{array}{l}2001.0(1329.6- \\
2001.0)\end{array}$ & $\begin{array}{l}985.4(581.8- \\
2001.0)\end{array}$ & $<0.001$ \\
\hline
\end{tabular}

\$ Right heart failure: defined according to the clinical diagnosis and ultrasonographic manifestations. \& Drugs with Nephrotoxicity: mainly included aminoglycosides, glycopeptides and colistin. ^, Data were collected before the development of AKI among patients who had developed AKI; The most abnormal

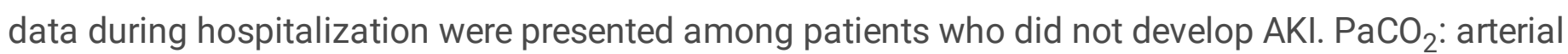
partial pressure of carbon dioxide; $\mathrm{PaO} 2 / \mathrm{FiO} 2$ ratio: the ratio between the arterial partial pressure of oxygen and the inspiratory concentration of oxygen; Data in bold indicated the comparisons with statistical significance.

\section{Table 2. Risk factors associated with acute kidney injury in the multivariate regression analysis among patients with Covid-19}

\begin{tabular}{|llll|}
\hline Variables & $\boldsymbol{\beta}$ & $\boldsymbol{p}$ value & OR (95\% Cl) \\
\hline Age & 0.05 & 0.0064 & $1.05(1.01-1.09)$ \\
\hline Sepsis & 1.04 & 0.0250 & $2.82(1.14-6.98)$ \\
\hline Drug with Nephrotoxicity & 0.98 & 0.0316 & $2.67(1.09-6.55)$ \\
\hline Respiratory support: IMV & 2.27 & 0.0002 & $9.72(2.93-32.24)$ \\
\hline Baseline SCR & 0.01 & 0.0018 & $1.01(1.00-1.02)$ \\
\hline 95\%Cl: 95\% confident interval & & & \\
\hline
\end{tabular}

95\%Cl: 95\% confident interval

Table 3. Clinical characteristics of patients with AKI who had improved renal function and those without during hospitalization 
Table 3. Clinical characteristics of patients with AKI who had improved renal function and those without during hospitalization

\begin{tabular}{|c|c|c|c|c|}
\hline Characteriatic & $\begin{array}{l}\text { Patients with AKI } \\
\qquad(\mathrm{N}=92)\end{array}$ & $\begin{array}{l}\text { Inproved } \\
(\mathrm{n}=16)\end{array}$ & $\begin{array}{c}\text { Not improved } \\
\quad(\mathrm{m}=76)\end{array}$ & $P$ value \\
\hline Age, median (IQR), y & $65(59-73)$ & $63(49-66)$ & $65(61-74)$ & 0.065 \\
\hline Time from admission to diagnoxiz of AKI, (dxy) & $9(5-12)$ & $5(3-9)$ & $9(6-14)$ & $=0.001$ \\
\hline Sex & & & & 0.059 \\
\hline Famalo & $30(32.6)$ & $2(12.5)$ & $28(36.8)$ & - \\
\hline Malo & $62(67.4)$ & $14(87.5)$ & $48(63.2)$ & - \\
\hline \multicolumn{5}{|l|}{ KDIGO staging } \\
\hline 1 & $13(14.1)$ & $3(18.8)$ & $10(13.2)$ & 0.850 \\
\hline 2 & $15(16.3)$ & $3(18.8)$ & $12(15.8)$ & $=0.999$ \\
\hline 3 & $64(69.6)$ & $10(62.5)$ & $54(71.1)$ & 0.706 \\
\hline \multicolumn{5}{|l|}{ Comorbidities } \\
\hline Hyperteavien & $45(48.9)$ & $8(50.0)$ & $37(48.7)$ & 0.924 \\
\hline Diabetes & $23(25.0)$ & $6(37.5)$ & $17(22.4)$ & 0.341 \\
\hline Cardiorascular diseaves & $9(9.8)$ & $0(0.0)$ & $9(11.8)$ & 0.324 \\
\hline Maliguncy & $10(10.9)$ & $2(12.50)$ & $8(10.5)$ & 0.651 \\
\hline Cercobronascular disease & $12(5.7)$ & $12(6.2)$ & $0(0.0)$ & $=0.999$ \\
\hline Crromic Kidney Diseave & $6(6.5)$ & $3(18.8)$ & $3(4.0)$ & 0.063 \\
\hline Chrouic Obstractivo Pulmonary Disease & $2(2.2)$ & $1(6.3)$ & $1(1.3)$ & $\mathrm{NA}$ \\
\hline Cempectivo Tissue Disease & $2(2.2)$ & $0(0.0)$ & $2(2.6)$ & $\mathrm{NA}$ \\
\hline \multicolumn{5}{|l|}{ Complication } \\
\hline Sepsis & $72(78.3)$ & $10(62.5)$ & $62(81.6)$ & 0.178 \\
\hline Right heart failure & $28(30.4)$ & $9(56.3)$ & $19(25.0)$ & 0.030 \\
\hline Dinaminated Lurarascular Congulatisu & $27(29.4)$ & $5(31.3)$ & $22(29.0)$ & $=0.999$ \\
\hline \multicolumn{5}{|l|}{ Treatment } \\
\hline CRRT & $52(56.5)$ & $9(56.3)$ & $43(56.6)$ & 0.981 \\
\hline Drug with Nephrotoxicity & $38(41.3)$ & $7(43.8)$ & $31(40.8)$ & 0.827 \\
\hline Respiratory suppert: COT & $2(2.2)$ & $1(6.3)$ & $1(1.3)$ & NA \\
\hline Respiratory support: HrN & $6(6.5)$ & $0(0.0)$ & $6(7.9)$ & $\mathrm{NA}$ \\
\hline Rospintary wapport: $\mathrm{NV}$ & $4(4.4)$ & $1(6.25)$ & $3(4.0)$ & NA \\
\hline Respiratory support IMV & $80(87.0)$ & $14(87.5)$ & $66(86.8)$ & $=0.999$ \\
\hline \multicolumn{5}{|l|}{ Laboratory Findings } \\
\hline Basoline ser:m crestinine (umol/L) & $75.5(59.8-102.8)$ & $88.6(54.4-229.8)$ & $72.3(61.8-90.8)$ & 0.169 \\
\hline Maximum $\mathrm{PaCO}_{2}(\operatorname{mrn} \mathrm{Hg})$ & $69.5(46.8-81.3)$ & $65.5(51.7-76.0)$ & $72.0(46.8-82.0)$ & 0.881 \\
\hline Maximmm PaCOst $=60 \mathrm{~mm} \mathrm{mig}_{\mathrm{g}}$ & $55(59.8)$ & $9(56.3)$ & $46(60.5)$ & 0.751 \\
\hline Mininem $\mathrm{P} 2 \mathrm{O} 2 \mathrm{FiO2}$ nato $(\mathrm{mmHg})$ & $73.0(62.8-138.6)$ & $133.5(106.0 .230 .0)$ & $67.0(62.0-88.5)$ & $\infty .001$ \\
\hline Minimum $\mathrm{PaO} 2 \mathrm{FiO} 2$ ratio $<150 \mathrm{mmHg}$ & $70(76.1)$ & $9(56.3)$ & $61(80.3)$ & 0.085 \\
\hline Meximem II-6 (pg ml) & $17.9(12.6-33.5)$ & $18.0(140-97.3)$ & $17.9(12.1-31.5)$ & 0.323 \\
\hline Maximum varum farritin (ng mil) & $2001.0(1329.6-2001.0)$ & $2001.0(1922.2-2001.0)$ & $2001.00(1295.5-2001.0)$ & 0.889 \\
\hline
\end{tabular}

SRight heart failure: defined according to the clinical diagnosis and ultrasonographic manifestations. \& Drugs
with Nephrotoxicity: mainly inchuded aminoglycosides, glycopeptides and colistin ^ . Data were collected before
the development of AKI among patients who had developed AKI; The most abnocmal data during hospitalization

Table 4. Clinical characteristics of patients with AKI who had survived and those not 


\begin{tabular}{|c|c|c|c|c|}
\hline Total & & Non-survivor & Survivor & \\
\hline Characteristic & $(N=210)$ & $(n=93)$ & $(n=117)$ & $\begin{array}{l}P \\
\text { value }\end{array}$ \\
\hline $\begin{array}{l}\text { Age, median (IQR), } \\
\text { yrs }\end{array}$ & $64(56-71)$ & $66(61-73)$ & $62(53-69)$ & 0.002 \\
\hline Sex & & & & 0.997 \\
\hline Female & 79 (37.6) & 35 (37.6) & $44(37.6)$ & - \\
\hline Male & $131(62.4)$ & $58(62.4)$ & $73(62.4)$ & - \\
\hline Severity of Covid-19 & & & & $<0.001$ \\
\hline Severe & $60(28.6)$ & $1(1.1)$ & $59(50.4)$ & - \\
\hline Critical & $150(71.4)$ & $92(98.9)$ & $58(49.6)$ & - \\
\hline \multicolumn{5}{|l|}{ Comorbidities } \\
\hline Hypertension & $98(46.7)$ & $43(46.2)$ & $55(47.0)$ & 0.911 \\
\hline Diabetes & $44(21.0)$ & $21(22.6)$ & $23(19.7)$ & 0.605 \\
\hline Cardiovascular diseases & $23(11.0)$ & $10(10.8)$ & $13(11.1)$ & 0.934 \\
\hline Malignancy & $14(6.7)$ & $9(9.7)$ & $5(4.3)$ & 0.119 \\
\hline Cerebrovascular disease & $12(5.7)$ & $7(7.5)$ & $5(4.3)$ & 0.313 \\
\hline Chronic Kidney Disease & $10(4.8)$ & $3(3.2)$ & $7(6.0)$ & 0.545 \\
\hline $\begin{array}{l}\text { Chronic Obstructive Pulmonary } \\
\text { Disease }\end{array}$ & $5(2.4)$ & $2(2.2)$ & $3(2.6)$ & NA \\
\hline Connective Tissue Disease & $2(1.0)$ & $1(1.1)$ & $1(0.9)$ & NA \\
\hline \multicolumn{5}{|l|}{ Complication } \\
\hline Sepsis & $112(53.3)$ & $72(77.4)$ & $40(34.2)$ & $<0.001$ \\
\hline Acute kidney injury & $92(43.8)$ & $65(69.9)$ & $27(23.1)$ & $<0.001$ \\
\hline AKI KDIGO stage 1 & $13(6.2)$ & $6(6.5)$ & $7(6.0)$ & 0.889 \\
\hline AKI KDIGO stage 2 & $15(7.1)$ & $10(10.8)$ & $5(4.3)$ & 0.070 \\
\hline AKI KDIGO stage 3 & $64(30.5)$ & $49(52.7)$ & $15(12.8)$ & $<0.001$ \\
\hline Right heart failure & $44(21.0)$ & $25(26.9)$ & $19(16.2)$ & 0.060 \\
\hline $\begin{array}{l}\text { Disseminated Intravascular } \\
\text { Coagulation }\end{array}$ & $32(15.2)$ & $26(28.0)$ & $6(5.1)$ & $<0.001$ \\
\hline Treatment & & & & \\
\hline
\end{tabular}




\begin{tabular}{|c|c|c|c|c|}
\hline $\begin{array}{l}\text { Continuous renal replacem } \\
\text { therapy }\end{array}$ & $54(25.7)$ & $39(41.9)$ & $15(12.82)$ & $<0.001$ \\
\hline Drug with Nephrotoxicity & $52(24.8)$ & $28(30.1)$ & $24(20.51)$ & 0.110 \\
\hline Respiratory support: COT & $41(19.5)$ & $0(0.00)$ & $41(35.04)$ & 0.287 \\
\hline Respiratory support: HFN & $22(10.5)$ & $3(3.23)$ & $19(16.24)$ & 0.002 \\
\hline Respiratory support: NIV & $29(13.8)$ & $10(10.75)$ & $19(16.24)$ & 0.252 \\
\hline Respiratory support: IMV & $118(56.2)$ & $80(86.0)$ & $38(32.5)$ & $<0.001$ \\
\hline \multicolumn{5}{|l|}{ Laboratory Findings } \\
\hline Baseline Scr(umol/L) & $69.7(55.9-85.9)$ & $71.1(58.4-90.8)$ & $69.0(54.4-81.3)$ & 0.165 \\
\hline $\begin{array}{l}\text { Maximum } \mathrm{PaCO} 2 \\
\mathbb{\mathrm { mmHH } \rrbracket}\end{array}$ & $52.0(39.0-73.8)$ & $71.0(54.0-79.0)$ & $43.0(38.0-54.0)$ & $<0.001$ \\
\hline $\begin{array}{l}\text { Maximum } \mathrm{PaCO} 2>= \\
60 \mathrm{mmHg}\end{array}$ & $82(39.1)$ & $61(65.6)$ & $21(18.0)$ & $<0.001$ \\
\hline Minimum P/F®mmHg $\rrbracket$ & $109.0(65.0-207.7)$ & $65.0(58.0-75.9)$ & $\begin{array}{l}190.0(130.0- \\
220.0)\end{array}$ & $<0.001$ \\
\hline $\begin{array}{l}\text { Minimum P/F } \\
<150 \mathrm{mmHg}\end{array}$ & $116(55.2)$ & $82(88.2)$ & $34(29.1)$ & $<0.001$ \\
\hline Maximum IL-6 (pg/ml) & $14.3(9.9-24.9)$ & $17.2(11.7-31.2)$ & $13.6(9.3-22.2)$ & 0.031 \\
\hline $\begin{array}{l}\text { Maximum serum ferritin } \\
(\mathrm{ng} / \mathrm{ml})\end{array}$ & $\begin{array}{l}1607.8(786.2- \\
2001.0)\end{array}$ & $\begin{array}{l}2001.0(1130.0- \\
2001.0)\end{array}$ & $\begin{array}{l}1000.7(590.2- \\
2001.0)\end{array}$ & $<0.001$ \\
\hline
\end{tabular}

Right heart failure: defined according to the clinical diagnosis and ultrasonographic manifestations. \& Drugs with Nephrotoxicity: mainly included aminoglycosides, glycopeptides and colistin. ^ , Data were collected before the development of AKI among patients who had developed AKI; The most abnormal data during hospitalization were presented among patients who did not develop $\mathrm{AKI}$. $\mathrm{PaCO}_{2}$ : arterial partial pressure of carbon dioxide; $\mathrm{PaO} 2 / \mathrm{FiO} 2$ ratio: the ratio between the arterial partial pressure of oxygen and the inspiratory concentration of oxygen

Data in bold indicated the comparisons with statistical significance.

Non-survivor: Deceased within 28 days of ICU admission

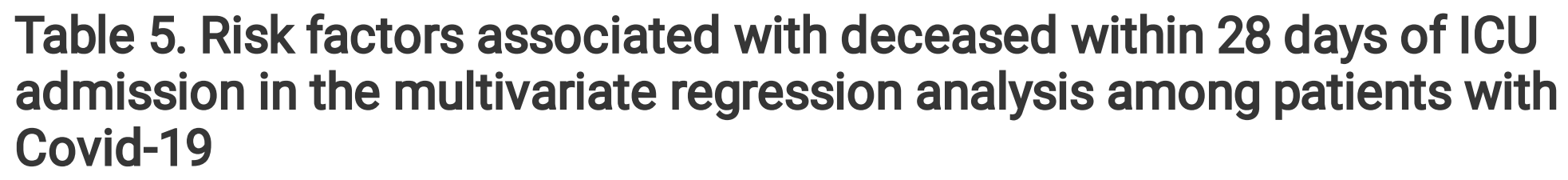




\begin{tabular}{|llll|}
\hline Variables & $\boldsymbol{\beta}$ & $\boldsymbol{p}$ value & OR $(95 \% \mathrm{Cl})$ \\
\hline Age & 0.06 & 0.0035 & $1.06(1.02-1.11)$ \\
\hline Severity of Covid-19: critical & 4.24 & 0.0008 & $69.16(5.86-815.79)$ \\
\hline AKI stage 3 & 1.67 & 0.0321 & $5.33(1.15-24.65)$ \\
\hline Min P/F $<150 \mathrm{mmHg}$ & 2.72 & 0.0000 & $15.21(4.72-49.07)$ \\
\hline
\end{tabular}

95\%Cl: $95 \%$ confident interval

Min P/F: Minimal PaO2/FiO2 ratio

\section{Figures}
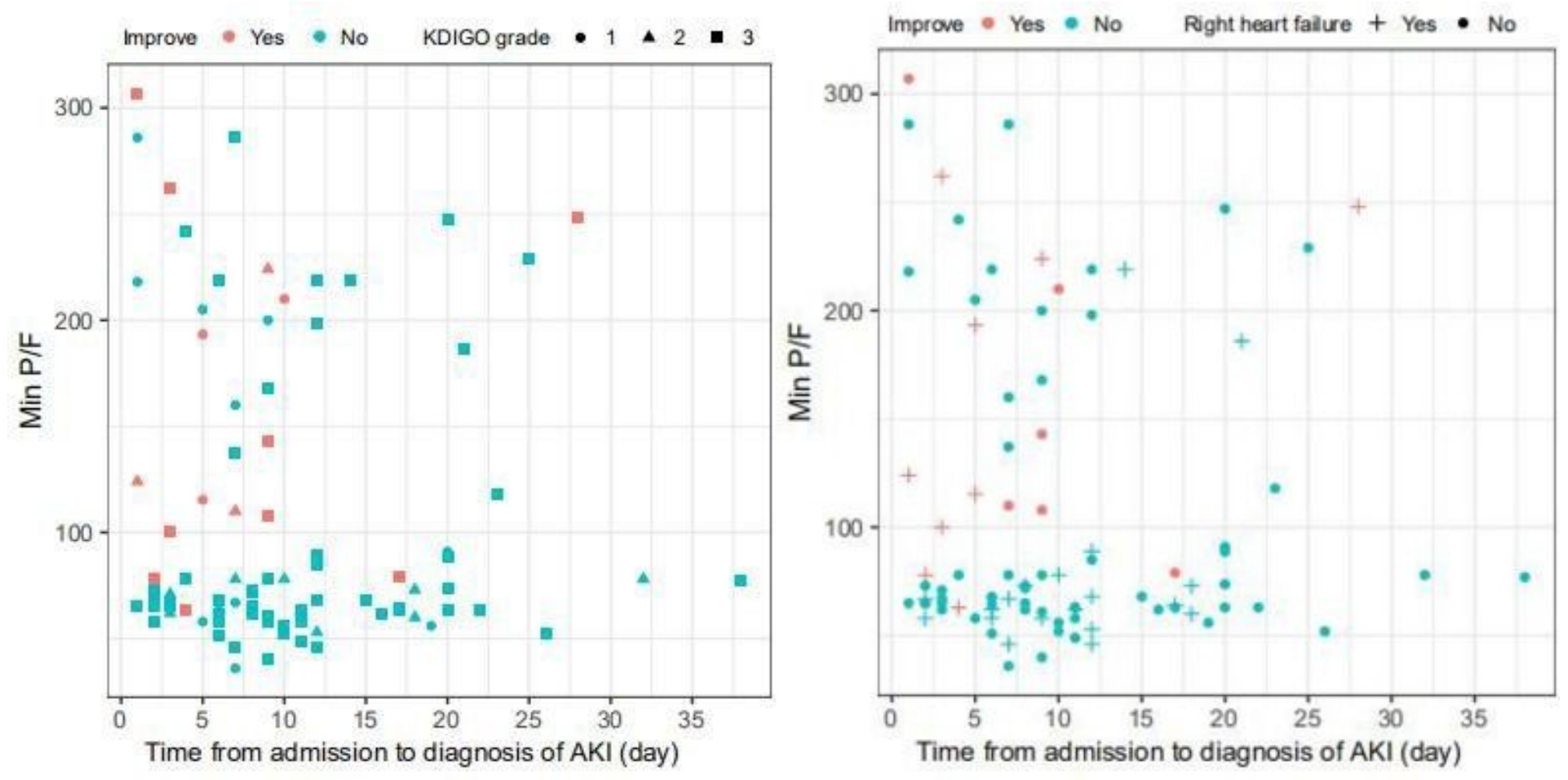

Figure 1

Association between the minimal $\mathrm{PaO} 2 / \mathrm{FiO} 2$ ratio, time from admission to $\mathrm{AKI}$ diagnosis, right heart failure and the outcomes of renal disorders in patients with Covid-19 who had acute kidney injury during hospitalization $\mathrm{A}$ (left). Association between the minimal Pa02/FiO2 ratio, time from admission to AKI diagnosis and the outcomes of renal disorder and the severity of acute kidney injury in patients with Covid-19 during hospitalization $\mathrm{B}$ (right). Association between the minimal $\mathrm{PaO} 2 / \mathrm{FiO} 2$ ratio, time from admission to AKI diagnosis and the outcomes of renal disorders and the presence of right heart failure in patients with Covid-19 who had acute kidney injury during hospitalization KDIGO: Kidney Disease: Improving Global Outcomes Min P/F: Minimal PaO2/FiO2 ratio 


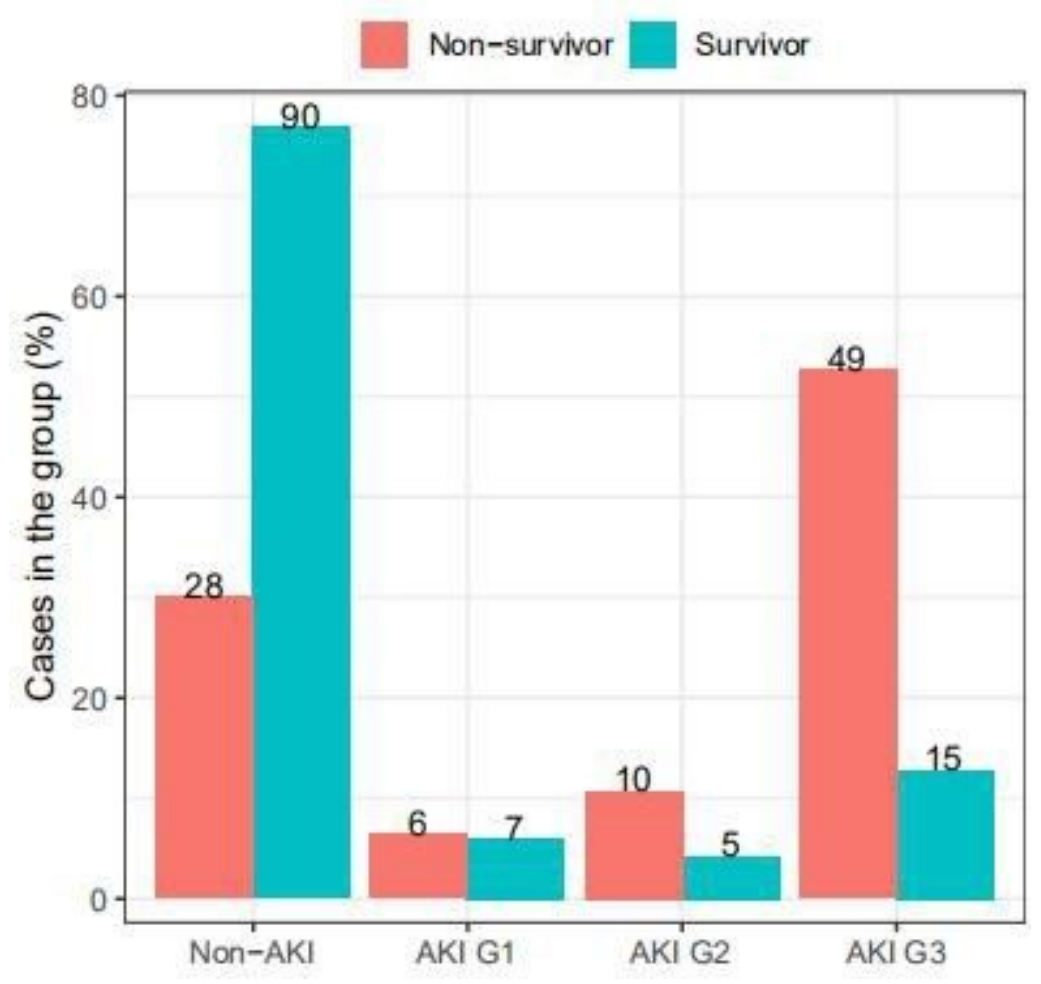

\section{Figure 2}

The proportion of patients with Covid-19 when stratified according to the survival status and the staging of the acute kidney injury AKI: Acute kidney injury; G: stage

\section{Supplementary Files}

This is a list of supplementary files associated with this preprint. Click to download.

- SupplementResults1.pdf 